УДК 622.276.43:678.745.842

\title{
ИЗУЧЕНИЕ МЕХАНИЗМА ПЕРЕРАСПРЕДЕЛЕНИЯ ФИЛЬТРАЦИОННЫХ ПОТОКОВ ПРИ ЗАКАЧКЕ СИНТЕЗИРОВАННЫХ СШИТЫХ ГЕЛЕЙ МЕТОДОМ РЕНТГЕНОВСКОЙ ТОМОГРАФИИ КЕРНА
}

\author{
Галкин Сергей Владиславович1, \\ doc_galkin@mail.ru \\ Кетова Юлия Анатольевна1, \\ ketova.pstu@gmail.com \\ Савицкий Ян Владимирович1, \\ yanpgu@gmail.com \\ Канг Ванли², \\ kangwanli@126.com \\ Бауыржан Сарсенбекулы², \\ sarsen_20-20@mail.ru \\ 1 Пермский национальный исследовательский политехнический университет, \\ Россия, 614990, г. Пермь, Комсомольский пр., 29. \\ 2 Китайский нефтяной университет (Восточный Китай), \\ Китай, 266580, Шаньдун, Циндао, Янцзы Вест Роуд, 66.
}

Актуальность. Для большинства месторождений Волго-Уральской нефртегазоносной провинции характерно преобладание высокообводненного фонда скважин, что определяет высокую востребованность в эфффективных технологиях снижения обводненности продукции скважин. Для этих целей за рубежом широко применяется технология предварительно сформированных гелей (preformed particle gel - PPG). Вместе с тем для внедрения технологии PPG на отечественных месторождениях необходимо учесть их геолого-технологические условия эксплуатации. Данная задача решена для условий низкотемпературных пластов при высокой минерализации пластовой воды. В публикации представлены результаты тестирования разработанного полимера PPG и стандартного полимерного заводнения на терригенном керне.

Цель: оценить возможность закачки предварительно сшитых полимерных частиц в терригенный керн, провести сравнительный анализ влияния суспензии полимерных частиц на поровое пространство керна с традиционным полимерным заводнением.

объект: терригенные керны Пермских месторождений, раствор водорастворимого полимера, суспензия частиц полимерного геля.

Методика. Фильтрационные испытания проводились на установке для исследования керна при пластовых условиях. Методом рентгеновской томограсфии керна установлен механизм воздействия суспензии частиц полимерного геля на пласт. Проведен сравнительный анализ результатов охвата воздействием на поры различных размеров для технологии PPG и полимерного заводнения.

Результаты. Авторами получены частицы полимерного геля (технология PPG), которые при закачке в виде суспензии через нагнетательную скважину способны кольматировать наиболее проницаемые интервалы. Состав полимера адаптирован $к$ условиям низкотемпературных пластов при высокой минерализации пластовой воды. Приведены результаты испытания разработанного полимера на керновых моделях. При исследованиях привлечены данные метода рентгеновской томографрии керна. Результаты томограсфических исследований позволили визуализировать и количественно рассчитать заполнение суспензией емкостного пространства породы с учетом размеров отдельных пор. Установлено, что разработанный полимер эфрфективно заполняет высокопроницаемые интервалы, перераспределяет потоки водной фразы в низкопроницаемые интервалы, значительно увеличивая охват порового пространства дисперсионной средой в сравнении с традиционным полимерным заводнением.

Ключевые слова:

Полимер, полиакриламид, выравнивание профилей приемистости пласта,

рентгеновская томография керна, частицы предварительно сшитого геля, обводненность.

\section{Введение}

Для большинства месторождений ВолгоУральской нефтегазоносной провинции (НГП) характерно преобладание высокобводненного фонда скважин, что обусловлено длительной историей добычи данного нефтегазоносного района. Это определяет высокую востребованность для месторождений комплексных технологий, направленных на снижение обводненности продукции скважин и вовлечение в разработку ранее недренируемых запасов [1]. Для снижения объемов добычи попутной воды применяют два основных подхода: ликвидация водопритоков в добывающей скважине и воздействие на профиль приемистости пласта через нагнетательную скважину. Практический опыт показывает, что при обводненности продукции скважины более 50 \% методы устранения водопритоков через мероприятия, реализуемые 
в добывающих скважинах, не всегда эффективны. Основной причиной этого является наличие множества зон водопритока, которые не могут быть устранены единичной обработкой [2]. Таким образом, для высокообводненных скважин востребованы технологии выравнивания профилей приемистости пласта, которые, в том числе, повышают коэффициент нефтеизвлечения.

Наиболее часто на отечественных месторождениях для выравнивания профилей приемистости пласта применяются технологии на основе полиакриламида (ПАА). Основными модификациями являются: частично гидролизованный ПАА; гидрофобномодифицированный ПАА, который благодаря межмолекулярному взаимодействию способен образовывать вязкие растворы, сохраняющие реологические характеристики при высокой скорости сдвига [3, 4]. Однако закачка растворов ПАА имеет ряд недостатков. В частности, реологические свойства растворов ПАА в значительной степени зависят от минерализации воды, на основе которой готовится состав для закачки. При большой скорости закачки и при прокачке насосными агрегатами полимерные цепи рвутся, что ведет к снижению вязкости раствора [5-7]. Кроме того, закачка раствора полимера требует стационарного дорогостоящего оборудования, что сказывается на себестоимости технологии.

В последние два десятилетия в мировой практике эффективно применяется технология закачки в нагнетательные скважины суспензии частиц предварительно сшитого геля (ЧПГ) на основе акриламида. Такой реагент, приготовленный на основе пластовой воды и ЧПГ, закачивается в нагнетательную скважину, при этом набухшие эластичные частицы полимера проникают в высокопроницаемые интервалы и блокируют их. При фильтрации полимерного геля по наиболее проницаемым пропласткам частицы накапливаются в обводненных интервалах, образуя полимерную «пробку». Это позволяет снизить обводненность добываемой продукции скважин и дает возможность более длительное время эксплуатировать обводнившийся фонд, увеличивая конечную долю нефтеизвлечения. Практический опыт и теоретические аспекты применения данного метода широко освещены в иностранной литературе, где технологию принято обозначать как PPG (preformed particle gel) [8-10].

На месторождениях Китая, центральной и северной Америки по технологии PPG для снижения обводненности коллекторов с проницаемостью более $500 \cdot 10^{-3}$ мкм $^{2}$ успешно проведено свыше 4000 скважинных операций. Необходимо отметить, что технология PPG является более экологичной в сравнении с полимерным воздействием на пласт, где для сшивки используются поливалентные металлы, например хром. Исследования в области деструкции полиакриламида показали, что наиболее токсичный в его составе мономер акриаламида, находясь в почве или в пластовой воде, полностью разрушается в период от 5 дней до 2 недель. В целом полимер типа PPG является экологически безопасным; находясь в аэробных условиях, подвергается микробиологической де- струкции и разрушается примерно в течение одного года [11].

На отечественных месторождениях Западной Сибири имеется некоторый ограниченный опыт применения схожих с PPG технологий в условиях высокотемпературных пластов $\left(60^{\circ}\right)$ с низкой минерализацией пластовой воды [12]. Однако месторождения Волго-Урала имеют иные геологические характеристики: низкие пластовые температуры (менее $30^{\circ}$ ) и повышенную минерализацию пластовой воды. В таких условиях, ввиду отсутствия необходимых гидролитических процессов в полиакриламиде, известные отечественные полимеры имеют низкую абсорбционную емкость, являются менее эластичными и трудно прокачиваются в пласт. С учетом этого авторами синтезирован и протестирован полимер, адаптированный к геологическим условиям залежей Пермского края. Синтез полимера PPG осуществлялся по технологическим стадиям, описанным в работе [13]. При этом использовались дополнительные сомономеры, обеспечивающие необходимые физико-химические характеристики полимера в условиях низкотемпературных пластов с минерализацией пластовой воды в диапазоне $200-230 \mathrm{r} / \mathrm{cm}^{3}$.

\section{Основные характеристики}

разработанного полимера PPG

Основой технологии PPG является закачка суспензии с частицами суперабсорбента, который способен впитывать воду. Предварительно сшитый гель представляет собой частицы с трехмерной структурой, в которой цепи ПАА сшиты между собой ковалентными полярными связями. В работе [14] приведены основные свойства частиц PPG: размер частиц в сухом виде от 10 мкм до нескольких мм; абсорбционная емкость 1-100 ра3; устойчивость к солям пластовой воды; стабильность при $140{ }^{\circ} \mathrm{C}$ в течение года; контролируемая кинетика абсорбции воды; регулируемая прочность частиц. При набухании полимерные частицы увеличиваются в объеме и становятся эластичными, двигаясь по пласту, они могут сжиматься и рваться [15]. По мере удаления от призабойной зоны пласта (ПЗП) в связи со значительным снижением давления нагнетания скорость перемещения частиц по пласту будет снижаться. При этом частицы полимерного геля будут накапливаться в высокопроницаемом интервале и образовать в удаленной зоне пласта (УЗП) полимерную «пробку». Применение технологии PPG позволяет увеличить время прохождения водного потока от нагнетательной до добывающей скважины, обеспечив равномерное распределение нагнетаемой воды по профилю пласта.

Полимер PPG получен авторами методом радикальной блок-полимеризации, при этом сшивка полимерных цепей проведена путем термической имидизации. Синтез проводился в растворе с высокой концентрацией мономеров. Условия проведения реакции позволяли получить полимерную массу с влажностью около 10-12 \%. После синтеза полимерная масса механически делилась на небольшие части и отправлялась на сушку при температуре $80{ }^{\circ} \mathrm{C}$ до 
твердого состояния. Далее проводилось механическое измельчение до необходимой фракции, которую получали путем классификации на ситах с нужным размером ячейки. Химический состав сшитого полимера запатентован [16].

Абсорбционная емкость полученного порошка PPG с гранулометрическим составом от 250 до 500 мкм составляет 35-37 г/г, что достигалось через 45-60 мин после контакта с моделью пластовой воды

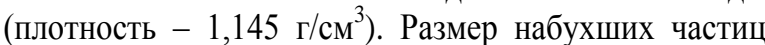
составил $1716 \pm 387$ мкм. На рис. 1, а представлено

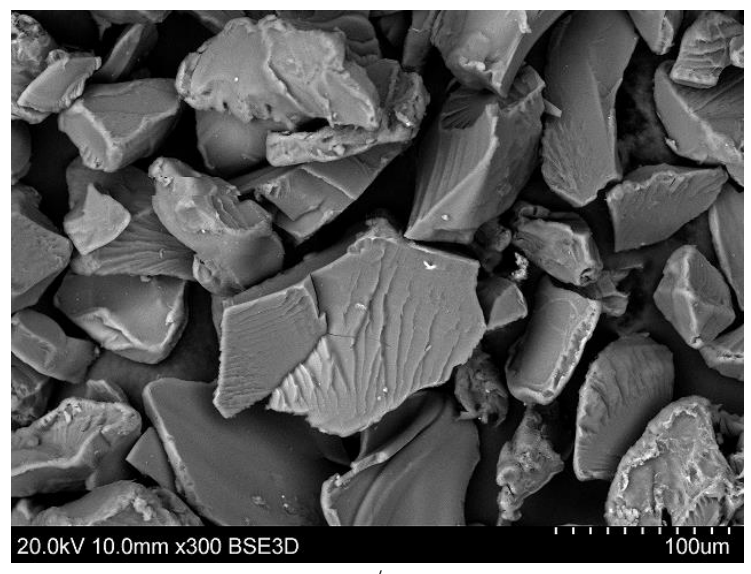

ala изображение частиц PPG в сухом виде, на рис. 1, бфото набухшей в $20 \%$-ом растворе хлористого натрия частицы, подверженной лиофильной сушке. Изображения получены на сканирующем электронном микроскопе разрешения 3-10 нм, модель «S$3400 \mathrm{~N} »$ фирмы «HITACHI».

Указанная выше фракция полученного PPG ранее была протестирована на трещиноватом карбонатном керне. В эксперименте PPG продемонстрировали способность заполнять трещины с раскрытостью в 18-20 раз меньше диаметра набухших частиц [17].

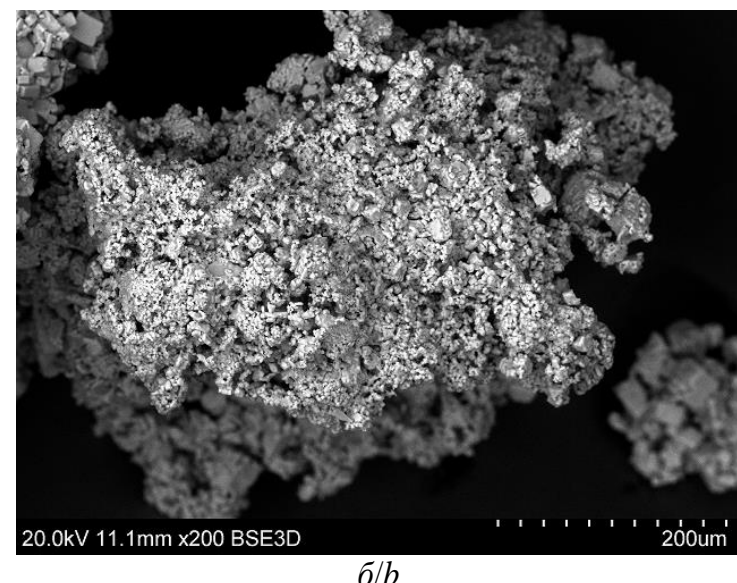

$\sigma / b$

Рис. 1. Фотографии с электронного сканирующего микроскопа частиц полимерного геля (фракция менее 250 мкм) в сухом виде (а) и после процесса абсорбции в соленой воде (20\% $\mathrm{NaCl}$ ) и сушки под вакуумом (б)

Fig. 1. Polymer gel particles (fraction less than 250 microns) a) dry; b) after swelling in salt water (20\% sodium chloride solution)

\section{Возможности изучения емкостного пространства горных пород методом рентгеновской томографии керна}

Метод рентгеновской томографии позволяет создавать объемные модели из серии рентгеновских снимков - полутоновых изображений, в которых различным оттенкам серого соответствуют участки с разной плотностью. Главным достоинством метода является то, что он позволяет без разрушения образца визуализировать структуру его емкостного пространства. В отличие от других методов, рентгеновская томография позволяет визуально оценивать количество и направление трещин, распределение каверн и крупных пор. Особенно перспективными являются возможности применения томографии при экспериментах, направленных на изменение емкостного пространства пород при воздействии на керн различных составов. Эксперимент при этом разбивается на следующие этапы: томографирование сухого образца; фильтрационные испытания путем закачки реагента; повторное томографирование образца. На этапе фильтрационных испытаний необходимо в реагенты предварительно вводить рентгеноконтрастные растворы, которые, за счет большей рентгеновской плотности, лучше визуализируются на томограммах. К настоящему времени имеется некоторый опыт таких экспериментов [18-21], результатом которых обычно является визуальная оценка входа реагентов в керн без представления количественных оценок заполнения емкостного пространства.
Для определения возможности закачки PPG в керн необходимо решить следующие задачи: определить условия закачки полимера PPG и его прохождения через керн, количественно оценить охват заполнения порового пространства реагентом при технологии PPG и при традиционном полимерном заводнении. Наиболее часто рентгеновская томография применяется в коллекторах карбонатного состава, с визуализацией в них преимущественно крупных пор, каверн и трещин. Применение метода в терригенных породах осложняется тем, что малые размеры большинства пор не позволяют их достоверно визуализировать. Однако для однородных песчаников и алевропесчаников средние диаметры пор находятся в пределах разрешающей способности метода. С учетом этого исследования в данной работе выполнены на примере высокопроницаемых песчаников.

Изменения порового пространства образцов в результате закачки полимеров оценивались путем сопоставления томограмм до и после проведения фильтрационных экспериментов. С этой целью на первом этапе проведены лабораторные испытания по введению рентгеноконтрастной метки в полимер. На основании имеющегося опыта использования меток для томографии кернов $[18,19]$ изначально в качестве маркера использовали иодид натрия, который вводили в полимер при синтезе. Однако в данных экспериментах ионы йода в необходимой концентрации ингибировали процесс полимеризации. В результате цвет меченного полимера на томограммах незначи- 
тельно отличался от порового пространства, что не позволило достоверно оценить проникновение в керн реагентов. Неудовлетворительные результаты также были получены при использовании в экспериментах в качестве рентгеноконтрастного состава сульфата бария и гидроксида бария.

После неудачных попыток пометить полимер проведены эксперименты по введению рентгеноконтрастной метки непосредственно в саму дисперсионную среду, что дало положительный результат. Наилучший эффект получен при использовании в качестве модели пластовой воды раствора иодида натрия с концентрацией 38 \% масс. (плотность 1,432 $\left.\Gamma / \mathrm{cm}^{3}\right)$. Примененная в данном случае высокая концентрация ионов йода позволила на томограммах на участках входа меченного реагента получить визуальный сигнал светло-серого до почти белого оттенка, который четко отличается как от порового пространства (черный цвет), так и от минерального скелета породы (более темный оттенок серого).

Используемые в экспериментах два образца стандартного керна (диаметром 30 мм) взяты из близких по глубине интервалов одной скважины. Они предварительно экстрагированы и насыщены раствором хлористого натрия (модель пластовой воды) плотностью 1,198 г/мл. Газоволюметрическим методом определен коэффициент открытой пористости $\left(\mathrm{K}_{\text {п-газ }}\right)$, который в обоих случаях составил 17,6 \%. Коэффициент проницаемости в сухих образцах $\left(\mathrm{k}_{1}\right)$ определялся путем закачки в них раствора хлорида натрия вязкостью 1,92 мПа с, $\mathrm{k}_{1}$ соответственно составил $583 \cdot 10^{-3}$ мкм $^{2}$ и $489 \cdot 10^{-3}$ мкм $^{2}$. Таким образом, оба образца представлены высокопроницаемыми коллекторами и имеют близкие фильтрационно-емкостные свойства (ФЕС), что позволяет использовать их для сравнения альтернативных технологий воздействия на пласт. Образец керна № 1 принят для тестирования технологии PPG, образец № 2 - для полимерного заводнения. Основные характеристики образцов приведены в табл. 1.

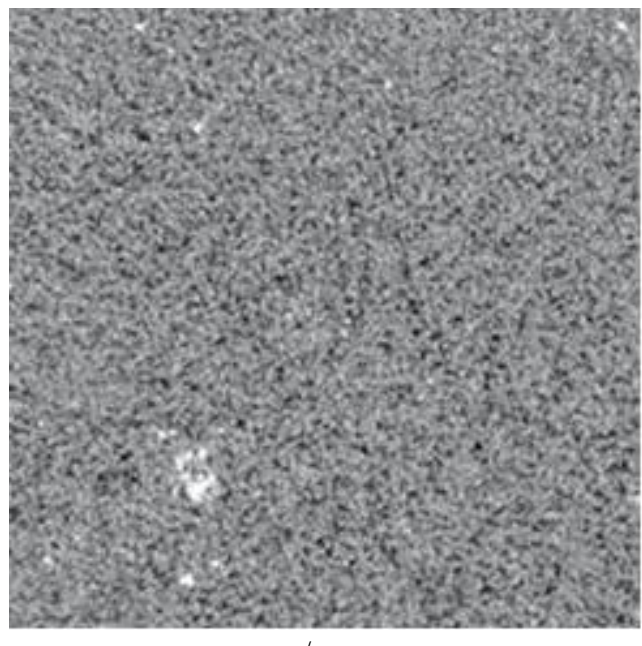

ala
Количественная оценка методом рентгеновской томографии керна эффективности блокировки порового пространства при применении технологии PPG и полимерного заводнения

Методика эксперимента включала в себя следующие последовательные операции. На первом этапе проводили томографирование кернов. Использование в экспериментах системы компьютерной томографии Nikon Metrology XТ Н 225 позволило на стандартном керне достоверно визуализировать поры размером до 0,04 мм. Процесс визуализации 3D модели реализовывался с использованием программного обеспечения Avizo Fire. Результаты томографирования до закачки в керны реагентов представлены в виде 2D срезов на рис. 2, $a$ (технология PPG) и рис. $3, a$ (полимерное заводнение). Поры в сухом состоянии образцов заполнены воздухом, ввиду чего визуализируются как наименее плотная среда черным цветом. Белым цветом визуализируются характеризующиеся наибольшей рентгеновской плотностью включения пирита. Сравнение томограмм в сухом состоянии (рис. 2, $a ; 3, a)$ показывает, что используемые в экспериментах образцы имеют сходную структуру минерального скелета и емкостного пространства, что подтверждается близкими значениями проницаемости и пористости $\left(\mathrm{K}_{\text {п-газ }}\right)$, определенные стандартным газоволюметрическим методом (табл. 1).

Высокое качество полученной цифровой 3D информации позволяет рассчитать видимые объемы емкостного пространства и определить по данным томографии пористость для сухого $\left(K_{\text {п-1том}}\right)$ и насыщенного (К тов представлены в табл. 1. Для образцов в сухом состоянии при анализе 3D-моделей можно визуализировать только поры диаметром более 0,06 мм, поры меньших диаметров достоверно по томографии не выделяются. Ввиду этого пористость наиболее крупных пор, которые фиксируются по томографии, составила для сухих образцов порядка $43-45$ \% от пол-

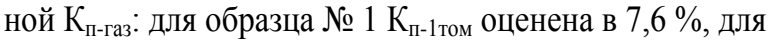
образца № $2-8,0 \%$.

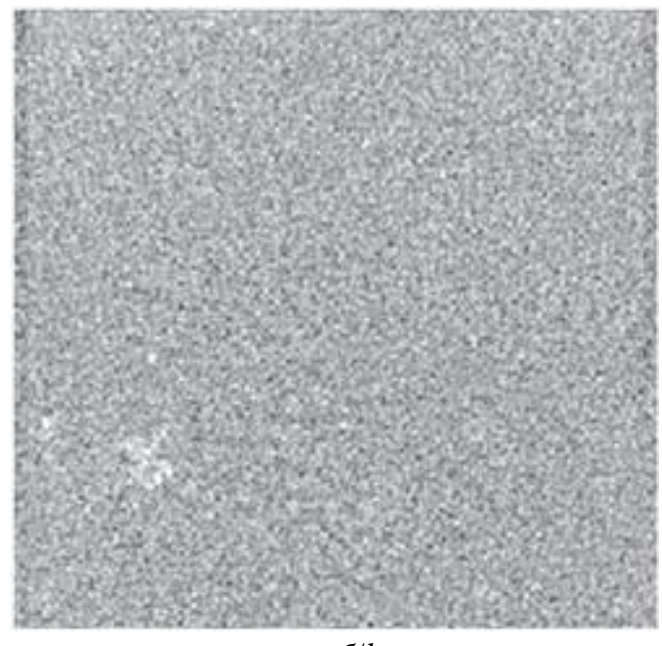

$6 / b$

Рис. 2. Томограммы образца керна № 1 при тестировании технологии $P P G$ в сухом состоянии (а) и после закачки реагента (б)

Fig. 2. Tomograms of core sample no. 1 before (a) and after (b) PPG injection 


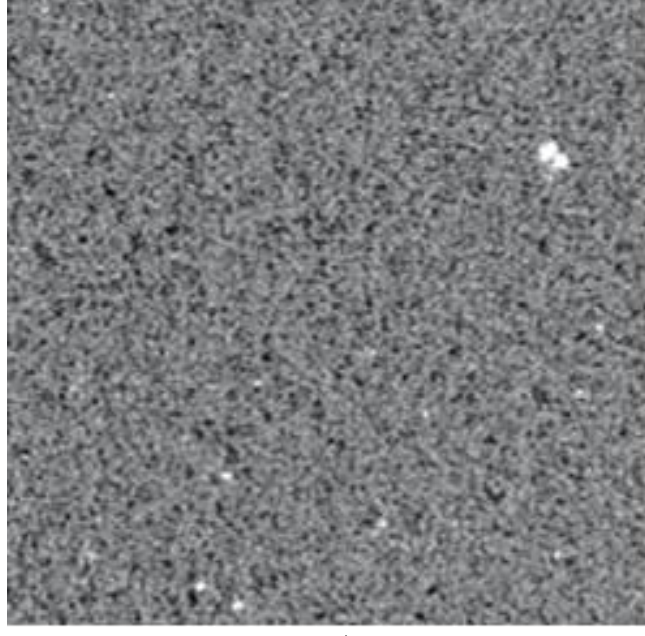

$a / a$

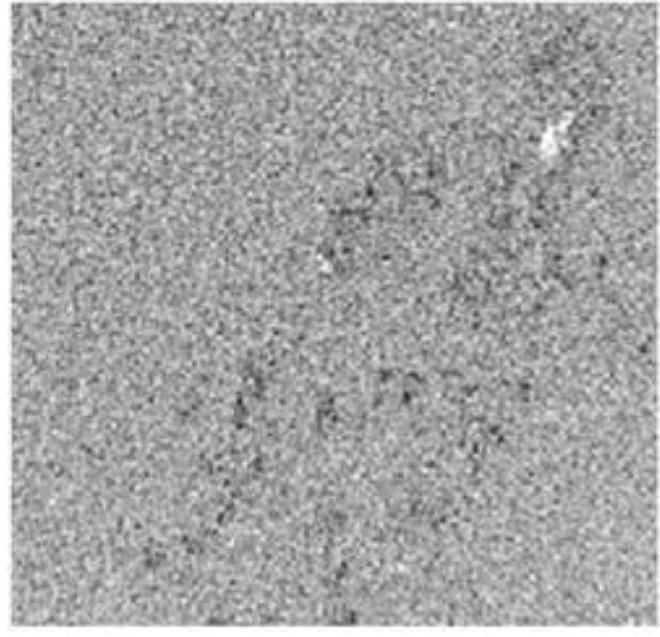

$\sigma / b$

Рис. 3. Томограммы образиа керна № 2 при тестировании технологии полимерного заводнения в сухом состоянии (a) и после закачки реагента (б)

Fig. 3. Tomograms of core sample no. 2 before (a) and after (b) polymer flooding

Таблица 1. Фильтрационно-емкостные характеристики образиов керна при тестировании технологии PPG и полимерного заводнения

Table 1. Core characteristics during experiments of $P P G$ and polymer flooding

\begin{tabular}{|c|c|c|c|c|c|}
\hline \multirow[b]{2}{*}{$\begin{array}{c}\text { Номер образца/тип } \\
\text { реагента } \\
\text { Sample num- } \\
\text { ber/reagent type }\end{array}$} & \multicolumn{3}{|c|}{$\begin{array}{c}\text { В сухом } \\
\text { состоянии } \\
\text { Dry core }\end{array}$} & \multicolumn{2}{|c|}{$\begin{array}{c}\text { После закачки } \\
\text { peaгента } \\
\text { After treatment }\end{array}$} \\
\hline & 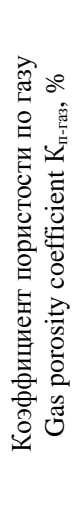 & 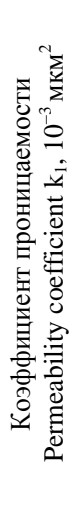 & 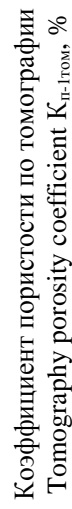 & 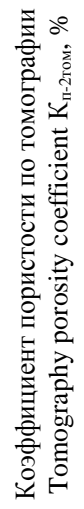 & 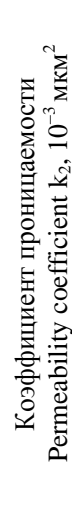 \\
\hline $\begin{array}{l}\text { Образец № 1/ } \\
\text { дисперсия PPG } \\
\text { Sample no. 1/ } \\
\text { PPG dispersion }\end{array}$ & 17,6 & 583 & 7,60 & 0,64 & 16 \\
\hline $\begin{array}{l}\text { Образец № 2/ } \\
\text { полимерный раствор } \\
\text { Sample no. 2/ } \\
\text { polymer solution }\end{array}$ & 17,6 & 489 & 8,02 & 4,26 & 24 \\
\hline
\end{tabular}

На следующем этапе с соблюдением пластовых условий проводились фильтрационные испытания на установке для исследования керна УИК-5ВГ. На основе раствора иодида натрия с добавлением полиакриламида марки SNF AN132 в концентрации 5000 ppm были приготовлены два состава с вязкостью 9,9 мПа с. В один из составов дополнительно вводился синтезированный порошок PPG фракционным составом менее 100 мкм в концентрации 1000 ppm. Таким образом были получены два меченных рентгено- контрастных состава, которые тестировались в двух независимых фильтрационных экспериментах. После закачки двух поровых объемов реагентов образцы керна изымались, помещались в герметичную упаковку, где хранились в течение нескольких часов до начала повторных томографических исследований.

При сравнении томограмм до и после закачки важно анализировать одни и те же участки (объемы) кернов. Это достигалось путем контроля на основе сопоставления реперов, которые в данном случае являются наиболее крупными включениями пирита, визуализируемыми на томограммах белым цветом. Сравнивая снятые в сухом и насыщенном состоянии томограммы, можно оценить для тестируемых составов степень охвата воздействием проницаемых интервалов.

Установлено, что характер заполнения емкостного пространства для технологии PPG и полимерного заводнения различен. Для технологии PPG объемы пор, которые отображались черным (рис. 2, a), стали окрашены светло-серым цветом (рис. 2, б). Заполнение пор рентгеноконтрастным составом произошло практически повсеместно. В эксперименте с полимерным заводнением поры заполнились менее равномерно. После закачки на томограммах прослеживаются участки черного цвета, в которых часть достаточно крупных пор осталась заполненной воздухом, а не реагентом (рис. 3, б). Эти выводы подтверждаются результатами расчетов по 3D-моделям.

Зная пористость до $\left(\mathrm{K}_{\text {п-1том}}\right)$ и после $\left(\mathrm{K}_{\text {п-2том }}\right)$ закачки реагента для визуализируемых по томографии размеров пор можно рассчитать коэффициент охвата пор воздействием реагента:

$$
\mathrm{K}_{\text {охв }}=\left(\mathrm{K}_{\text {п-1том }}-\mathrm{K}_{\text {п-2том }}\right) / \mathrm{K}_{\text {п-1том }} \text {. }
$$

В среднем при тестировании технологии PPG меченой дисперсионной средой оказались не заполненными лишь 0,6 \% (К $7,6 \%$ пор $\left(\mathrm{K}_{\text {п-1том }}\right)$, что соответствует $\mathrm{K}_{\text {охв }}=91,6 \%$. Для полимерного заводнения результаты охвата порового пространства воздействием заметно ниже: 


$$
\mathrm{K}_{\text {п-1том }}=8,0 \% ; \mathrm{K}_{\text {п-2том }}=4,3 \% ; \mathrm{K}_{\text {охв }}=46,9 \% .
$$

Еще более показательны результаты расчетов заполняемости емкостного пространства для различных диапазонов размеров пор, которые приведены в табл. 2 . Для технологии PPG поры с диаметром более 0,08 мм во всех интервалах заполнены дисперсионной средой на 94 \% и выше. Для пор диаметром от 0,07 до 0,08 мм $\mathrm{K}_{\text {охв }}$ составил $93,1 \%$; для минимального размера пор $\left(0,06-0,07\right.$ мм) $K_{\text {охв }}$ чуть ниже $-80,9 \%$. Результаты томографии показывают высокий охват порового пространства воздействием при закачке суспензии PPG для всех размеров видимых по томографии пор.

При тестировании полимерного заводнения относительно удовлетворительный охват - от 62 до $73 \%$ установлен только для самых крупных пор более 0,10 мм. Для пор диаметром от 0,09 до 0,10 мм $\mathrm{K}_{\mathrm{oxв}}=61,0 \%$; от 0,08 до 0,09 мм $-\mathrm{K}_{\text {охв }}=52,4 \%$. Для пор меньших диаметров $\mathrm{K}_{\text {охв }}$ начинает резко падать: $\mathrm{K}_{\text {охв }}=35,9 \%$ в интервале от 0,07 до 0,08 мм; $K_{\text {охв }}=12,2 \%$ в интервале от 0,06 до 0,07 мм (табл. 2). Необходимо заметить, что размер более 0,06 мм характеризует достаточно крупные поры, т. е. эксперимент с полимерным заводнением в целом свидетельствует о неудовлетворительном охвате воздействием порового пространства керна.

Таблица 2. Распределение коэффициентов пористости по данным томографии до и после закачки реагентов и расчетного охвата воздействием дисперсионной средой для различных размеров диаметра пор

Table 2. Distribution of porosity coefficients according to tomography before and after reagents injection and the estimated coverage by the dispersion medium for various pore diameters

\begin{tabular}{|c|c|c|c|c|c|c|}
\hline \multirow{3}{*}{$\begin{array}{c}\text { Диаметр } \\
\text { пор, мм } \\
\text { Pore } \\
\text { diameter, mm }\end{array}$} & \multicolumn{3}{|c|}{$\begin{array}{l}\text { Технология PPG } \\
\text { PPG technology }\end{array}$} & \multicolumn{3}{|c|}{$\begin{array}{l}\text { Полимерное заводнение } \\
\text { Polymer flooding }\end{array}$} \\
\hline & $\mathrm{K}_{\text {п-1том }}$ & $\mathrm{K}_{\text {п-2том }}$ & $\kappa_{\text {oXB }}$ & & $\mathrm{K}_{\text {п-2том }}$ & $K_{\text {oxB }}$ \\
\hline & \\
\hline $0,06-0,07$ & 2,6303 & 0,5024 & 80,9 & 1,6396 & 1,4394 & 12,2 \\
\hline $0,07-0,08$ & 0,7857 & & 93,1 & 1,9783 & 1,2688 & 35,9 \\
\hline $0,08-$ & 1,2196 & & 96,3 & 0,6713 & & 52,4 \\
\hline $0,09-$ & 1,0858 & & 98,4 & 1,0702 & & 61,0 \\
\hline $0,10-$ & 0,6175 & & 99,0 & 0,9734 & & 69,5 \\
\hline $0,11-$ & 3916 & & 99,2 & 0,5404 & & 68,3 \\
\hline $0,12-$ & 0,3668 & & 99,2 & 0,4120 & & 68,3 \\
\hline $0,13-$ & 0,1935 & & 99,2 & 0,2267 & & 71,3 \\
\hline 0,14 & 1036 & & 98,8 & 0,1600 & 450 & 71,9 \\
\hline 0,15 & 0844 & & 98,7 & 0,1163 & & 71,8 \\
\hline $0,16-$ & 0508 & & 99,0 & 0,0628 & 0,0 & 61,9 \\
\hline $0,17-$ & 0236 & & 97,9 & 0,0531 & & 66,1 \\
\hline $0,18-$ & 0160 & & 98,8 & 0,0325 & 0,0 & 65,5 \\
\hline 0,19 & 0112 & & 94,6 & 0,0231 & 0,0069 & 70,1 \\
\hline $0,20-$ & 0079 & & 97,5 & 0,0172 & 0,0051 & 70,3 \\
\hline $0,21-$ & 0,0059 & 0,0004 & 93,2 & 0,0143 & 0,0042 & 70,6 \\
\hline $0,22-0$, & 0,0027 & 0,000 & 94,4 & 0,0094 & 0,0026 & 72,3 \\
\hline $0,23-0$, & 0,0010 & 0,00005 & 95,0 & 0,0089 & 0,0026 & 70,8 \\
\hline $0,24-0,25$ & 0,0006 & 0,00000 & 100,0 & 0,0076 & 0,0021 & 72,4 \\
\hline Итого & 7,60 & 0,64 & 91,6 & 8,02 & 4,26 & 46,9 \\
\hline
\end{tabular}

Таким образом, в результате применения метода рентгеновской томографии керна установлено, что при одинаковых объемах закачки тестируемых реа- гентов суспензия PPG создает большие фильтрационные сопротивления в сравнении с полимерным заводнением, за счет чего потоки дисперсионной среды, содержащие меченный компонент, перераспределяются в низкопроницаемые интервалы.

\section{Анализ результатов фильтрационных экспериментов при применении технологии PPG \\ и полимерного заводнения}

Результаты фильтрационных испытаний закачки реагентов в виде графиков изменения проницаемости образцов и перепада давления от прокачки поровых объемов жидкости представлены на рис. 4. Ход прокачки полимеров можно разбить на три последовательных этапа. Первоначально раствор хлорида натрия вязкостью 1,92 мПа.с прокачивался через образец при поддержании объемного расхода $5 \mathrm{~cm}^{3} / \mathrm{Mин}$ до стабилизации перепада давления. На данном этапе определялась проницаемость образца до воздействия $\mathrm{k}_{1}$ по формуле (1)

$$
k_{1}=\frac{q \cdot \mu \cdot l}{F \cdot \Delta P} \cdot \frac{1000}{60}, 10^{-15} \mathrm{~m}^{2},
$$

где $q$ - расход флюида, см ${ }^{3} /$ мин; $\mu$ - вязкость жидкости, мПа·с; $l$ - длина образца, см; $F$ - площадь сечения образца, $\mathrm{cm}^{2} ; \Delta P$ - перепад давления, атм; $\frac{1000}{60}-$ коэффициент пересчета.
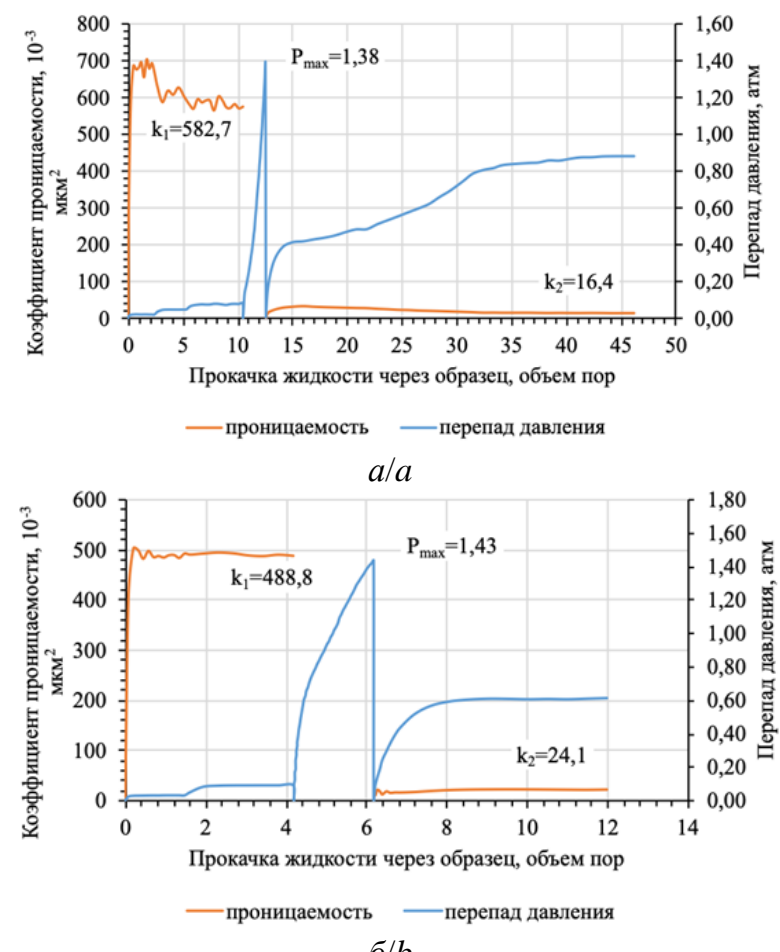

$\sigma / b$

Pис. 4. Результаты фильтрационных испытаний технологии PPG (a) и полимерного заводнения (б)

Fig. 4. Results of core flooding tests of PPG technology (a) and polymer flooding $(b)$

На втором этапе из разделительной поршневой емкости проводилась закачка суспензий на основе 
тестируемых реагентов при скоростях $1 \mathrm{~cm}^{3} / \mathrm{Mин}$ Поршневая система при этом ввиду возможности осаждения со временем полимеров была ориентирована строго вертикально. В каждом из испытаний суммарно закачено по два поровых объема исследуемой жидкости. На рис. 4 данный этап характеризуется резким возрастанием $\Delta \mathrm{P}$ с быстрым достижением максимума, который в проведенных экспериментах сопоставим (PPG - 1,38 атм; полимерное заводнение - 1,43 атм). После завершения закачки реагента керны вынимались из установки для промывки торцов от частиц полимера.

На заключительном этапе возобновлялась прокачка водного раствора хлорида натрия через образец при объемном расходе $5 \mathrm{~cm}^{3} /$ мин до стабилизации $\Delta \mathrm{P}$ с повторным определением проницаемости модели пласта после воздействия полимером $\left(\mathrm{k}_{2}\right)$. В целом можно говорить о том, что проницаемость кернов после закачки реагентов в обоих случаях кратно снизилась. Причем после воздействия PPG для изначально более проницаемого керна $\left(583 \cdot 10^{-3}\right.$ мкм $^{2}$ против $489 \cdot 10^{-3}$ мкм $\left.^{2}\right)$ величина $\mathrm{k}_{2}$ ниже, чем при полимерном заводнении $\left(16 \cdot 10^{-3}\right.$ мкм $^{2}$ против $\left.24 \cdot 10^{-3}\right)$. Соответственно, остаточный фактор сопротивления $\mathrm{F}_{\mathrm{rr}}$ $\left(\mathrm{k}_{2} / \mathrm{k}_{1}\right)$, характеризующий снижение проницаемости при испытаниях, для технологии PPG составил 0,027 ; для полимерного заводнения - 0,049. Это свидетельствует о том, что эффективность блокировки проницаемых интервалов при использовании полимера PPG в 1,5 раза выше.

По мере прокачки реагента PPG от 14 до 33 поровых объемов установлен постепенный линейный рост $\Delta \mathrm{P}$ (рис. $4, a$ ). В этот период частицы полимера перемещались по высокопроницаемым зонам, формируя в керне полимерный «экран». После завершения данного этапа давление закачки вышло на плато со значением $\Delta \mathrm{P}=0,9$ атм, что можно интерпретировать как окончание формирования «экрана» и его равномерное перемещение по керну. В совокупности результаты данного эксперимента с учетом проницаемости керна, размера частиц и их концентрации свидетельствуют, что при переменной закачке реагента PPG и пластовой воды риск блокировки ПЗП должен быть минимален.

При тестировании полимерного заводнения на этапе измерения $\mathrm{k}_{2}$, наоборот, установлен резкий рост $\Delta \mathrm{P}$ сразу после прокачки двух поровых объемов и выход на «плато» при значении 0,6 атм (рис. 4, б). Столь быстрое достижение максимального давления нагнетания свидетельствует о том, что вязкий раствор в данном случае практически беспрепятственно фильтровался через проницаемые пропластки. В этом случае большинство проницаемых каналов не блокируется, в них не создается необходимого полимерно-

\section{СПИСОК ЛИТЕРАТУРЫ}

1. Гумерова Г.Р., Яркеева Н.Р. Анализ эффективности применения вязкоупругого поверхностно-активного состава на месторождениях Западной Сибири // Известия Томского политехнического университета. Инжиниринг георесурсов. - 2019. T. 330. - № 1. - C. 19-25. DOI: 10.18799/24131830/2019/1/47

2. Liu Yu., Bai B., Wang Ye. Applied technologies and prospects of conformance control treatments in China // Oil \& Gas Science and го экрана, обеспечивающего фильтрационное сопротивление для перераспределения потоков в низкопроницаемые зоны. Таким образом, сравнительный анализ результатов фильтрационных испытаний показывает, что полимерное заводнение менее эффективно в сравнении с технологией PPG.

\section{Заключение}

В результате фильтрационных экспериментов на керновых моделях установлено, что разработанный полимер PPG эффективно снижает проницаемость. Коэффициент проницаемости керна для технологии PPG снизился в 36 раз с $583 \cdot 10^{-3}$ до $16 \cdot 10^{-3}$ мкм $^{2}$, тогда как для полимерного заводнения лишь в 20 раз - с $489 \cdot 10^{-3}$ до $24 \cdot 10^{-3}$ мкм $^{2}$. Анализ хода фильтрационных испытаний показывает, что реагент PPG формирует в проницаемых зонах полимерный «экран», который затем равномерно перемещается по керну, перераспределяя фильтрационные потоки в низкопроницаемые пропластки. Частицы PPG при закачке в пласт сохраняют свою подвижность, что свидетельствует о минимальном риске нежелательной блокировки ПЗП. При эксперименте со стандартным полимерным составом вязкий раствор быстро фильтровался через проницаемые пропластки, в необходимой степени, не блокируя их и не создавая полимерной «пробки».

Томографические исследования керна показали, что в эксперименте при закачке реагента PPG достигнут максимальный охват воздействием крупных пор (более 0,06 мм) меченной дисперсионной жидкостью (92\%), тогда как при закачке традиционного раствора полиакриламида он в 2 раза ниже (46 \%). Применение метода рентгеновской томографии керна позволило количественно рассчитать степень охвата воздействием дисперсионной жидкостью емкостного пространства породы с учетом размеров отдельных пор.

Таким образом, в результате проведенных томографических и фильтрационных экспериментов на керновых моделях установлено, что частицы полимерного геля PPG эффективно блокируют проницаемые интервалы. Экспериментально подтверждено свойство реагента перераспределять потоки в низкопроницаемые менее доступные зоны пласта. Полимерный состав PPG рекомендован к проведению опытно-промышленных испытаний на промысловых объектах.

Статья подготовлена по материалам исследований, проводимых при финансовой поддержке Минобрнауки России в рамках ФЦП «Исследования и разработки по приоритетным направлениям развития научнотехнологического комплекса России на 2014-2020 годыl» (Уникальный идентификатор проекта RFMEFI62120Х0038).

Technology - Rev. IFP Energies nouvelles. - 2010. - V. 65. № 6. - P. 859-878. DOI: 10.2516/ogst/2009057

3. Нажису, Ерофеев В.И. Исследование и применение технологии полимерного заводнения для повышения нефтеотдачи пластов // Успехи современного естествознания. - 2018. № 11 (часть 2). - C. 420-424. DOI: 10.17513/use.36963

4. Wever D.A.Z., Picchinoni F., Broekhuis A.A. Polymers for enhanced oil recovery: a paradigm for structure-property 
relationship in aqueous solution // Progress in polymer science. 2011. - № 36. - P. 1558-1628. DOI: 10.1016/j.progpolymsci. 2011.05.006

5. Полимерное заводнение для увеличения нефтеотдачи на месторождениях легкой и тяжелой нефти / А. Тома, Б. Саюк, Ж. Абиров, Е. Мазбаев // Территория «НЕФТЕГАЗ». - 2017. № 7-8. - C. 58-67.

6. Review on polymer flooding: rheology, adsorption, stability, and field applications of various polymer systems / M.S. Kamal, A.S. Sultan, U.A. Al-Mudaiyedh, I.A. Hussein // Polymer Reviews. - 2015. - P. 1-40. DOI: 10.1080/15583724.2014.982821

7. Sheng J.J., Leonhardt B., Azri N. Status of polymer-flooding technology // J of Canadian Petroleum Technology. - 2015. V. 54. - Iss. 02. - P. 116-126. DOI: 10.2118/174541-PA

8. Анализ эффективности применения заводнения нефтеносных пластов на основе водорастворимого полиакриламида и предварительно сшитых полиакриламидных частиц / Ю.А. Кетова, Б. Бай, А.Л. Казанцев, С.В. Галкин // Вестник ПНИПУ. Геология. Нефтегазовое и горное дело. - 2019. - Т. 19. - № 3. C. 251-262. DOI: 10.15593/2224-9923/2019.3.5

9. Zhu D., Bai B., Hou J. Polymer gel systems for water management in high-temperature petroleum reservoirs: a chemical review // Energy Fuels. - 2017. - № 31. - P. 13063-13087. DOI: 10.1021/acs.energyfuels.7b02897

10. Bai B., Zhou J., Yin M. A comprehensive review of polyacrylamide polymer gels for conformance control // Petroleum exploration and development. - 2015. - V. 42. - Iss. 4. - P. 525-532. DOI: 4.10.1016/S1876-3804(15)30045-8

11. Polyacrylamide degradation and its implications in environmental / B. Xiong, R.D. Loss, D. Shields, T. Pawlik, R. Hochreiter, A. Zydney, M. Kumar // Systems npj Clean Water. - 2018. V. 1. - Iss. 17. - P. 1-9. DOI: 10.1038/s41545-018-0016-8

12. Каушанский Д.А. Многофункциональная инновационная технология повышения нефтеотдачи пластов на поздней стадии разработки «Темпоскрин-люкс» // Георесурсы. Геоэнергетика. Геополитика. - 2014. - T. 1. - № 9. URL: http://oilgasjournal.ru/vol_9/kaush-adv.pdf (дата обращения: 19.04.2020).

13. Preformed particle gel for conformance control: factors affecting its properties and applications / B. Bai, L. Li, Yu Liu, Zh. Wang,
H. Liu // SPE/DOE Symposium on Improved Oil Recovery. Tulsa, Oklahoma, 17-21 April, 2004. DOI: 10.2118/89389-MS

14. Bai B., Wei M., Liu Yu. Field and lab experience with a successful preformed particle gel conformance control technology // SPE Production and Operations Symposium. - Oklahoma City, Oklahoma, USA: Society of Petroleum Engineers, 23-26 March, 2013. DOI: $10.2118 / 164511-M S$

15. Preformed particle gel for conformance control: transport mechanism through porous media / B. Bai, Y. Liu, J.-P. Coste, L. Li // SPE Reservoir Evaluation \& Engineering. - 2007. V. 10. - № 02. DOI: 10.2118/89468-PA

16. Способ разработки нефтяного пласта: пат. РФ № 2729652. 2020. Бюл. № 23.

17. Тестирование технологии предварительно сшитых частиц полимерного геля для ограничения водопритоков на фильтрационных керновых моделях / Ю.А. Кетова, Б. Бай, Г.П. Хижняк, Е.А. Гладких, С.В. Галкин // Записки горного института. 2020. - T. 241. - C. 91-96. DOI: 10.31897/PMI.2020.1.91

18. Galkin S.V., Kolychev I.J., Savitskiy Ya.V. Potentialities of investigation of reservoir hydrophobization by compilation of X-ray core tomography and lateral logging // Russian Geology and Geophysics. - 2019. - № 10. - P. 1496-1507.

19. Исследование смачиваемости коллекторов нефтяных месторождений методом рентгеновской томографии керна / А.А. Ефимов, Я.В. Савицкий, С.В. Галкин, Е.В. Соболева, В.Ш. Гурбанов // Научные труды НИПИ Нефтегаз ГНКАР. 2016. - T. 4. - № 4. - C. 55-63.

20. Geochemical controls on wettability alteration at pore-scale during low salinity water flooding in sandstone using X-ray micro computed tomography / Y. Chen, N.K. Jha, D. Al-Bayati, M. Lebedev, M. Sarmadivaleh, S. Iglauer, A. Saeedi, Q. Xie // Fuel. - 2020. - № 0271. - Статья № 117675. DOI: 10.1016/j.fuel.2020.117675

21. Two-phase flow visualization under reservoir conditions for highly heterogeneous conglomerate rock: A core-scale study for geologic carbon storage / K.-Y. Kim, J. Oh, W.S. Han, K.G. Park, Y.J. Shinn, E. Park // Scientific Reports. - 2018. - V. 8. - № 1. DOI: $10.1038 / \mathrm{s} 41598-018-23224-6$

Поступила 22.10.2020 г.

\section{Информация об авторах}

Галкин C.B., доктор геолого-минералогических наук, профессор, декан горно-нефтяного факультета Пермского национального исследовательского политехнического университета.

Кетова Ю.А., научный сотрудник, младший научный сотрудник кафедры нефтегазовых технологий Пермского национального исследовательского политехнического университета.

Савицкий Я.B., старший преподаватель кафедры геологии нефти и газа Пермского национального исследовательского политехнического университета.

Канг Ванли, доктор технических наук, профессор Китайского нефтяного университета.

Бауырж⿻ан Сарсенбекулы, $\mathrm{PhD}$, приглашенный научный сотрудник Китайского нефтяного университета. 
UDC 622.276.43:678.745.842

\section{X-RAY ANALYSIS OF CONFORMANCE CONTROL TECHNOLOGY BASED ON PREFORMED PARTICLE GEL TREATMENT}

Sergey V. Galkin1,

doc_galkin@mail.ru

Yulia A. Ketova ${ }^{1}$, ketova.pstu@gmail.com

Yan V. Savitskiy 1 , yanpgu@gmail.com

Kang Wanli2, kangwanli@126.com

Bauyrzhan Sarsenbekuly², sarsen_20-20@mail.ru

1 Perm National Research Polytechnic University, 29, Komsomolsky avenue, Perm, 614990, Russia.

2 School of Petroleum Engineering, China University of Petroleum (East China), 66, West Road Qingdao, Changjiang Shandong, 266580, China.

The relevance. Most fields of the Volga-Ural oil and gas province are characterized by high water cut of wells that determines the high demand of effective technologies for decreasing excess water production. For these purposes, preformed particle gel (PPG) technology is widely used abroad. However, for PPG application in domestic oil fields, it is necessary to take into account their geological and technological operating conditions. This problem is solved for conditions of low-temperature formations with high salinity of formation water. The publication presents the test results of the developed PPG polymer and standard polymer flooding on sandstone core.

The main aim is to evaluate the possibility of injection of PPG into a terrigenous core, to conduct a comparative analysis of PPG treatment with traditional polymer flooding.

Object: terrigenous cores of Perm deposits, a solution of a water-soluble polyacrylamide, PPG.

Method. Filtration tests were carried out on the filtration installation UIK-5VG. The X-ray tomography method was used to estimate the pore space changing after PPG treatment and compare it with traditional polymer flooding.

Results. The authors synthesized particles of a polymer gel (PPG technology) for reservoir conformance control. During application of PPG through the injection well the gel particles are able to move through the near well bore zone and block the high permeable reservoir zones, that leads to redistribution of water flows to the low-permeable zones. The composition of the polymer is adapted to the conditions of low-temperature formations with high salinity of formation water. The article presents the test results of the developed polymer on core models. The studies involved the data from the method of $X$-ray tomography of the core. The results of tomographic studies made it possible to visualize and quantitatively calculate the filling of the core pore space with a suspension, taking into account the size of individual pores. It was established that the developed polymer fills highly permeable intervals much more efficiently than standard polyacrylamide flooding.

Key words:

Polymer, polyacrylamide, reservoir profile conformance control, core X-ray tomography, preformed particle gel, water cut.

The article was prepared on the basis of the research conducted with financial support from the Russian Ministry of Education and Science within the framework of the Federal Target Program «Research and Development in Priority Directions for the Development of the Russian Science and Technology Complex for 2014-2020» (Unique project identifier RFMEFI62120X0038).

\section{REFERENCES}

1. Gumerova G.R., Yarkeeva N. R. Analysis of the efficiency of applying viscous-elastic surface-active composition on the fields of Western Siberia. Bulletin of the Tomsk Polytechnic University. Geo Assets Engineering, 2019, vol. 330, no. 1, pp. 19-25. In Rus. DOI: $10.18799 / 24131830 / 2019 / 1 / 47$

2. Liu Yu., Bai B., Wang Ye. Applied technologies and prospects of conformance control treatments in China. Oil \& Gas Science and Technology - Rev. IFP Energies nouvelles, 2010, vol. 65, no. 6, pp. 859-878. DOI: $10.2516 /$ ogst/2009057.

3. Najisu, Erofeev V.I. Research and application of polymer flooding technology to enhance oil recovery. Advances in Current Natural Science, 2018, no. 11, pp. 420-424. In Rus. DOI: $10.17513 /$ use. 36963
4. Wever D.A.Z., Picchioni F., Broekhuis A.A. Polymers for enhanced oil recovery: a paradigm for structure-property relationship in aqueous solution. Progress in Polymer Science, 2011, vol. 36, pp. 1558-1628. DOI: 10.1016/j.progpolymsci.2011.05.006.

5. Toma A., Sayuk B., Abirov J., Mazbayev E. Polymer flooding for increasing of oil recovery in light and heavy oil fields. Territory «NEFTEGAZ», 2018, no. 7-8, pp. 58-67. In Rus.

6. Kamal M.S., Sultan A.S., Al-Mudaiyedh U.A., Hussein I.A. Review on polymer flooding: rheology, adsorption, stability, and field applications of various polymer systems. Polymer Reviews, 2015, pp. 1-40. DOI: 10.1080/15583724.2014.982821.

7. Sheng J.J., Leonhardt B., Azri N. Status of polymer-flooding technology. J of Canadian Petroleum Technology, 2015, vol. 54, no. 02 , pp. 116-126. DOI: $10.2118 / 174541-P A$. 
8. Ketova Y.A., Bai B., Kazantsev A.L., Galkin S.V. Analysis of the efficiency of waterflooding of oil reservoirs using water-soluble polyacrylamide and preliminary cross-linked polyacrylamide particles. Perm Journal of Petroleum and Mining Engineering, 2019, vol. 19, no. 3, pp. 260-273. In Rus. DOI: 10.15593/22249923/2019.3.5.

9. Zhu D., Bai B., Hou J. Polymer gel systems for water management in high-temperature petroleum reservoirs: a chemical review. Energy Fuels, 2017, no. 31, pp. 13063-13087. DOI 10.1021/acs.energyfuels.7b02897.

10. Bai B., Zhou J., Yin M. A comprehensive review of polyacrylamide polymer gels for conformance control. Petroleum exploration and development, 2015, vol. 42, no. 4, pp. 525-532. DOI: 4.10.1016/S1876-3804(15)30045-8.

11. Xiong B., Loss R.D., Shields D., Pawlik T., Hochreiter R., Zydney A., Kumar M. Polyacrylamide degradation and its implications in environmental. Systems npj Clean Water, 2018, vol. 1, no. 17, pp. 1-9. DOI: 10.1038/s41545-018-0016-8.

12. Kaushanskii D.A Multifunctional innovation technology for enhanced oil recovery at a late stage of development of Temposkrinlux. Georesursy. Geoenergetika. Geopolitika, 2014, vol. 1, no. 9 , In Rus. Available at: http://oilgasjournal.ru/vol_9/kaush-adv.pdf (accessed 19 April 2020).

13. Bai B., Li L., Liu Y., Wan Zh., Liu H. Preformed particle gel for conformance control: factors affecting its properties and applications. SPE/DOE Symposium on Improved Oil Recovery. Tulsa, Oklahoma, 17-21 April, 2004. DOI: 10.2118/89389-MS.

14. Bai B., Wei M., Liu Yu. Field and lab experience with a successful preformed particle gel conformance control technology. SPE Production and Operations Symposium. Oklahoma City, Oklahoma, USA, 23-26 March, 2013. DOI: 10.2118/164511-MS.
15. Bai B., Liu Y., Coste J.-P., Li L. Preformed particle gel for conformance control: transport mechanism through porous media. SPE Reservoir Evaluation \& Engineering, 2007, vol. 10, no. 02. DOI: 10.2118/89468-PA.

16. Susanov Ya.M., Ustkachkintsev E.N., Rozhkova Yu.A. Sposob razrabotki neftyanogo plasta [Method of oil layer development]. Patent RF no. 2729652, 2020.

17. Ketova Y., Bai B., Khizhnyak G., Gladkikh E., Galkin S. Testing of preformed particles polymer gel technology on core filtration models to limit water inflows. Journal of Mining Institute, 2020, vol. 241, pp. 91-96. In Rus. DOI: 10.31897/PMI.2020.1.91.

18. Galkin S.V., Kolychev I.J., Savitskiy Ya.V. Potentialities of investigation of reservoir hydrophobization by compilation of X-ray core tomography and lateral logging. Russian Geology and Geophysics, 2019, no. 10, pp. 1496-1507.

19. Efimov A.A., Savitskiy Ya.V., Galkin S.V., Soboleva E.V., Gurbanov V.Sh. Study of wettability of reservoirs of oil fields by the method of x-ray tomography core. SOCAR Proceedings, 2016, no. 4, pp. 55-63. In Rus.

20. Chen Y., Jha N.K., Al-Bayati D., Lebedev M., Sarmadivaleh M., Iglauer S., Saeedi A., Xie Q. Geochemical controls on wettability alteration at pore-scale during low salinity water flooding in sandstone using X-ray micro computed tomography. Fuel, 2020, no. 271, article 117675. DOI: 10.1016/j.fuel.2020.117675.

21. Kim K.-Y., Oh J., Han W.S., Park K.G., Shinn Y.J., Park E. Twophase flow visualization under reservoir conditions for highly heterogeneous conglomerate rock: a core-scale study for geologic carbon storage. Scientific Reports, 2018, vol. 8, no. 1, article 4869. DOI: $10.1038 / \mathrm{s} 41598-018-23224-6$.

Received: 22 October 2020.

\section{Information about the authors}

Sergey V. Galkin, Dr. Sc., professor, dean of the Mining and Petroleum Department, Perm National Research Polytechnic University.

Yulia A. Ketova, researcher, junior researcher, Perm National Research Polytechnic University.

Yan V. Savitskiy, senior lecturer, Perm National Research Polytechnic University.

Kang Wanli, Dr. Sc., professor, China University of Petroleum (East China).

Bauyrzhan Sarsenbekuly, PhD, visiting researcher, China University of Petroleum (East China). 